\title{
RANDOMIZED CONTROL STUDY OF REDUCED DOSE OF ORAL VS VAGINAL MISOPROSTOL WITH MIFEPRISTONE FOR EARLY MTP
}

\author{
Rishika Raj ${ }^{1}$, Anup Pradhan ${ }^{2}$ \\ ${ }^{1}$ Assistant Professor, Department of Obstetrics \& Gynaecology, Sikkim Manipal Institute of Medical Sciences. \\ ${ }^{2}$ Associate Professor, Department of Obstetrics \& Gynaecology, Sikkim Manipal Institute of Medical Sciences.
}

\section{ABSTRACT}

\section{OBJECTIVE}

The present study was aimed to compare the efficacy of oral vs vaginal administration of $600 \mu \mathrm{g}$ of misoprostol following pretreatment with $200 \mathrm{mg}$ of mifepristone to terminate pregnancy up to 63 days in a non-blinded, randomised trial.

\section{PATIENTS AND METHODS}

In this study, 100 women requesting for MTP within 63 days of pregnancy were included. Initially 200 mg mifepristone was given orally; then after 48 hours those in oral group were given three tablets ( $200 \mu \mathrm{g}$ each) of misoprostol and those in vaginal groups came back for vaginal administration. Complete abortion rate, induction-abortion interval, duration of vaginal bleed and adverse effects were compared.

\section{RESULTS}

Complete abortion rate were similar in both groups ( $94 \%$ in vaginal vs. $86 \%$ in oral group, $p=0.3178)$. However, in pregnancy of less than 49 days, complete abortion was more successful in vaginal (97\%) compared to oral group (87\%). Mean inductionabortion interval was 3.1 hours in vaginal as compared to 3.7 hours in oral misoprostol group, but was not statistically significant. On comparing complete abortion within 4 hours of misoprostol, a statistically significant difference was observed (93.6\% in vaginal vs. $79 \%$ in oral l group, $\mathrm{p}=0.029$ ). The adverse effects of misoprostol were significantly higher in oral group.

\section{CONCLUSION}

$200 \mathrm{mg}$ mifepristone followed 48 hours later by $600 \mathrm{mg}$ of misoprostol is an effective means for safe termination of pregnancy up to 63 days of gestation with vaginal route being better in terms of having early completion of abortion (within 4 hours), thus being better and more acceptable as a day care procedure.

\section{KEYWORDS}

Vaginal Misoprostol, Mifepristone, Medical Termination of Pregnancy.

HOW TO CITE THIS ARTICLE: Raj R, Pradhan A. "Randomized control study of reduced dose of oral vs vaginal misoprostol with mifepristone for early MTP." Journal of Evolution of Medical and Dental Sciences 2015; Vol. 4, Issue 105, December 31; Page: $17078-17082$, DOI: $10.14260 /$ jemds/2015/2588

\section{INTRODUCTION}

Medical termination is the abortion of pregnancy through medications without the surgery beyond 49 days of conception. It offers immense prospective for improving abortion access and safety, as it requires a less extensive infrastructure than surgical abortion. Increased cost, longer duration of bleeding and a longer waiting period for completion are the demerits of medical termination but the women underwent medical termination feels slightly superior comfort than the surgical abortion.[1]

Globally, 30 million abortions are done every year and safety of the procedure is consequently of global public health importance.[2] Medical termination regimens have a welldocumented failure rate. [3] Research has been unremitting to progress the medical abortion regimen as its instigation.

Financial or Other, Competing Interest: None.

Submission 14-12-2015, Peer Review 15-12-2015,

Acceptance 24-12-2015, Published 31-12-2015.

Corresponding Author:

Anup Pradhan,

Department of Obstetrics \& Gynaecology,

Sikkim Manipal Institute of Medical Sciences,

Tadong, Gangtok-737102,

Sikkim, India.

E-mail: anup0428@gmail.com

DOI:10.14260/jemds/2015/2588
Now, the universally used regimen all through the world is mifepristone followed by a prostaglandin analogue, usually misoprostol.

Medical termination of pregnancy with a combination of mifepristone and prostaglandin is a relatively safe and effective choice to suction evacuation up to 63 days of gestation.[4-6]

In the absence of progesterone, embryo is expelled by a prostaglandin-mediated mechanism and hence Progesterone is sustaining an early pregnancy. Epostane, a $3 \beta$ hydroxysteroid dehydrogenase inhibitor, prevents progesterone synthesis however requires dosing each $6 \mathrm{hrs}$ for 7 days to result abortion. ${ }^{7,8]}$

Mifepristone, a derivative of norethindrone, (RU 486) is the initial vastly efficient progesterone receptor antagonist, binds to the progesterone receptor with an affinity equal to progesterone itself. ${ }^{[9]}$ but does not activate the receptor, thus exerts antiprogestin effect.

Mifepristone affects the uterus and cervix during early human pregnancy with precise actions that make it a potential for abortion. Mifepristone alters the endometrium by directly effecting the capillary endothelial cells of the deciduas, there is no direct effect on the trophoblast. ${ }^{[10]}$

This results in separation of the trophoblast from the decidua causing bleeding and a decrease in Human Chorionic Gonadotropin (hCG) secretion into the maternal circulation. 
The decidual action also increases prostaglandin release in vitro.[11] and in vivo.[12] Mifepristone also sensitizes the uterus to prostaglandins and increases the efficacy of prostaglandins. ${ }^{[13]}$

Misoprostol is a synthetic analogue of prostaglandin E1 (PGE1), chemically it is methyl $1 \alpha, 16$ dihydroxy-16 methyl-9oxoprost-13-en-1-oate. It was approved by the US-FDA for the prevention of Non-Steroidal Anti-Inflammatory Drug (NSAID)induced gastric ulcers.

The prostaglandin appears to soften the cervix by increasing the proteoglycan content and changing the biophysical properties of collagen. It has been shown to be an effective myometrial stimulant of the pregnant uterus, selectively binding to the EP2/EP3-prostanoid receptors. mifepristone to softens the cervix to expel the products of conception. ${ }^{[14]}$

It has also been demonstrated that the oral misoprostol dose of $400 \mathrm{mg}$ was inadequate when the length of pregnancy was more than 7 weeks.[15,16] Studies have also shown that vaginal administration of misoprostol after pre-treatment with mifepristone resulted in higher complete abortion compared to oral dose.[17] Hence in the present study comparison of the therapeutic regimens of mifepristone with a reduced dose 600 $\mu \mathrm{g}$ of oral versus vaginal misoprostol in terms of efficacy and safety for medical termination of early pregnancy were undertaken.

\section{MATERIALS AND METHODS}

This study was conducted in the Department of Obstetrics and Gynaecology of Central Referral Hospital-Sikkim Manipal Institute of Medical Sciences with the Ethics Committee approval at the Central Referral Hospital. This study was a randomized longitudinal study with 100 pregnant women requesting for MTP within 63 days of pregnancy and computer generated random number sequence was used for randomization of women.

A written informed consent was taken from all the women who opted for medical termination using pills were further counselled regarding the procedure and visits for follow-up for the medical termination of pregnancy. All the women were explained that in case of incomplete abortion or continuation of pregnancy, surgical uterine evacuation was advised.

\section{INCLUSION AND EXCLUSION CRITERIA}

Women included in the study were $>18$ years, duration of pregnancy not more than 63 days, Hemoglobin greater than 10 $\mathrm{g} / \mathrm{L}$ and a willingness to undergo surgical abortion. Those women with history or evidence of adrenal pathology, steroid dependent cancer, porphyria, diastolic $\mathrm{BP}>95 \mathrm{~mm} \mathrm{Hg}$, bronchial asthma, arterial hypotension; history or evidence of thromboembolism, severe/recurrent liver disease; suspected ectopic pregnancy; presence of IUCD; and lack of access to emergency services were excluded from the study.

Computer generated random number sequence was use for randomization of women to one of the two group. All the pregnant women were divided into two group's namely oral misoprostol and vaginal misoprostol women. During the $1^{\text {st }}$ day, Ultrasonography pelvis was performed for all women to confirm intrauterine pregnancy and weeks of gestation. After demographic characteristics, i.e., history, physical examination and hemoglobin, blood group and Rh type investigations, 200mg mifepristone was orally administered to all the pregnant women. Oral misoprostol group women swallowed 3 tablets of misoprostol $200 \mu \mathrm{g}$ each 48 hours after mifepristone administration, whereas in the vaginal misoprostol group women 3 tablets of misoprostol $200 \mu$ g each were deeply inserted into vagina 48 hours after mifepristone administration. All the women were monitored for 1 hour and informed to go home. Both the group of the pregnant women were advised to attend the hospital unless bleeding occurs.

All were informed to record the onset of bleeding, timing of passage of tissue, duration of bleeding and side effects for the next 14 days. At the end of $14^{\text {th }}$ day, general, vaginal examination and Ultrasound were performed to confirm complete abortion in the out-patient department. If pelvic ultrasound showed evidence of incomplete abortion, missed abortion or continuing pregnancy, suction evacuation was done.

All the women were instructed to report to the hospital if vaginal bleeding occurs in more than two soaked sanitary pads in one hour for two successive hours. Success was defined as complete expulsion of the products of conception with no need for surgical intervention. Failure was when patient required a surgical intervention for incomplete abortion, missed abortion, continuing pregnancy or if suction evacuation was done even for haemostatic purposes.

Outcome, i.e. Complete or Incomplete Abortion, onset of bleeding (any amount of vaginal bleeding was considered as onset of bleeding), duration of bleeding, Induction - abortion interval (Induction-abortion interval was defined as the time (in hrs) between misoprostol administration and passage of products of conception) and side effects following misoprostol administration were noted as the outcome variables.

\section{STATISTICAL ANALYSIS}

All the values were expressed as mean \pm standard deviation. For difference between means of different data arrays paired or unpaired two-tailed Student's t-test was performed, depending on the circumstance. Chi-square $\left(\chi^{2}\right)$ test was done for evaluation of the significance of difference in distribution of different data arrays. Differences between various parameters among different groups or subgroups were considered statistically significant if the $p$ value was less than 0.05 .

\section{RESULTS}

The basic demographic characteristics of the pregnant women namely age (Table-1), parity, days of gestation, history of previous mode of delivery and abortions showed no statistical significant difference between the oral and the vaginal groups. $94 \%$ women in the vaginal misoprostol group and $86 \%$ of women in the oral misoprostol had complete abortion with $\mathrm{p}$ value 0.318 with no statistical significance.

There was no incidence of missed abortion or continuing pregnancy in either group. There was no statistically significance difference in respect to outcome regarding parity, period of gestation, previous history of abortion and previous mode of delivery (Table-2).

The mean induction - abortion interval was shown in Table-3. The mean induction-abortion interval in the oral misoprostol group was 3.6 (In hours) and 3.1 (In hours) in the vaginal misoprostol group. 
The onset of bleeding and the duration of bleeding after misoprostol administration were almost similar in both the groups (Table-4). The onset of bleeding was 3.6 (in hours) in the oral and 3.1 (In hours) in the vaginal group whereas the duration of bleeding was found to be 9.15 and 9.14 in oral and vaginal groups. However, when analysis was done where cut off for induction to abortion was kept up to $4 \mathrm{hrs}$ it was found that $91 \%$ in vaginal group had induction-abortion interval of less than 4 hours as compared to $69 \%$ in the oral group, this was statistically significant with p-value 0.029 .

The incidence of nausea and vomiting was significantly higher in the oral group with $36 \%$ and $24 \%$ and $52 \%$ and $32 \%$ in vaginal group respectively. It was found that these higher numbers of adverse events were statistically significant between these groups with p-value 0.017 (Table-3).

\section{DISCUSSION}

Medical termination offers vast potential for improving abortion access and safety, as it requires less wide infrastructure than surgical abortion. In addition, it is devoid of anesthesia and Operation Theater, and maintains patient's need for privacy.

The disadvantages would be that the women requires at least 3 visits to the hospital, erratic result in few patients, longer period of bleeding, and probable hazard of fetal deformity if it fails to cause abortion. The other factors abdominal cramps and heavy bleeding, duration of bleeding (average 7-10 days), and the need to follow-up after 2 weeks for clinical examination and sonography, prevents the women from accepting the medical termination.

Over a decade, for the medical abortion of pregnancy, antiprogesterone mifepristone followed by a prostaglandin analogue administration is in clinical practice and this combination was found to be effective up to 63 days. In a sample size of 263 pregnant women with 63 days of amenorrhoea of clinical study, resulted in a higher complete abortion rate of $95 \%$ with vaginal administration of $800 \mathrm{mg}$ misoprostol after pretreatment with mifepristone than the oral route with $87 \% .{ }^{[18]}$ Schaff et al. have also reported that $97 \%$ absolute abortion rate with $800 \mathrm{mg}$ misoprostol selfadministered vaginally after pretreatment with $200 \mathrm{mg}$ mifepristone at home in 933 women with pregnancy up to 8 week in their trial.[19]

Our study also showed the similar success rates indicating both oral and vaginal routes were found to be equally effective. No statistical significance difference was observed in terms of the side effects with both the routes of administration.

A satisfactory abortion rate of $90-95 \%$ was found with the oral administration of $200 \mathrm{mg}$ mifepristone followed by 36 $48 \mathrm{hrs}$ vaginal administration of $800 \mu \mathrm{g}$ misoprostol.[20] Due to its efficient, economical and steady at room temperature, vaginal misoprostol is widely used off label for medical abortion even it is not licensed for medical abortion. [21]

The comparison of pharmacokinetics of systemic bioavailability of vaginal versus oral administration indicated that the area under the serum level of misoprostol concentration versus time curve was higher than oral misoprostol.[22] Vaginal tablets dissolve partly, and pharmacokinetic studies have confirmed wide variability in serum levels with vaginal administration.[22,23]
In the present study, overall $86 \%$ of women in the oral misoprostol group showed complete abortion with complete abortion of $87 \%$ and $82 \%$ in women with gestational age $\leq 49$ days and 50-63 days respectively. Comparable results were already reported by El-Refaey et al.[17] by $600 \mathrm{mg}$ mifepristone followed by $800 \mu \mathrm{g}$ misoprostol.

With our vaginal misoprostol group, 94\% had complete abortion with abortion rates of $97 \%$ in women with gestational age $\leq 49$ days and $83 \%$ in women with gestational age 50-63 days. Similar studies by Schaff et al.[19] and Ashok et al.[20] using 200mg mifepristone but with a slightly higher dose of vaginal misoprostol of $800 \mu \mathrm{g}$ have shown similar results.

The interval between the administration of the drug and induction of abortion has an important bearing on acceptability from the patient's perspective and overall management strategy.[17] In this study, mean inductionabortion interval in the oral misoprostol group was 3.7 hours and 3.1 hours in the vaginal misoprostol group which was statistically insignificant. Of the 63 women who appreciated passage of products of conception, it was seen that $81 \%$ of women had abortion within 4 hours of misoprostol administration while the rest $19 \%$ had it after 4 hours. One subject who had reported passage of product of conception had incomplete abortion.

Among the 85 women who had complete abortion, 62 appreciated the passage of products of conception. In these subjects, the products of conception passed within 4 hours in $69 \%$ of those who were administered misoprostol orally while in the vaginal group $91 \%$ passed the product of conception within 4 hours.

This passage of products of conception started after 4 hours in 31\% in the oral misoprostol group and $9 \%$ in the vaginal misoprostol group. These differences were statistically significant [p-value (chi-square test) $=0.029$ ]. Similar observations were noted by El-Refaey et al who found that proportion of patients who had abortion within 4 hours after the administration of misoprostol was significantly higher among those receiving the drug vaginally than those receiving it orally.[17]

Bleeding during and after the abortion naturally constitutes the maximum distress for both women and their care provider. The amount of bleeding considered normal during medical abortion might considerably exceed a woman's previous experience of bleeding.

Passage of clots in altering sizes and amounts occur frequently during the discharge of contents during abortion may make the women more uncomfortable.[24] The mean duration of bleeding was found to be same between the oral and vaginal group. Similarly large trials found that bleeding lasts an average of 8-17 days. Rarely, this can be significant requiring blood transfusion.[25]

Dose and the route of administration of prostaglandin are the major cause for an adverse effect during medical abortion occurs in the smooth muscle throughout the body.[26] Relatively higher incidence of nausea and vomiting were associated with the oral misoprostol when than the vaginal route at the same dose of administration.[17]

Huge number of studies have been documented already with $20-65 \%$ nausea and vomiting $10-44 \%$ respectively.[25,27] Our study also supports the previous trials with similar patterns of adverse effects with no statistically significant difference between the groups. El Refaeyet al.[17] also showed 
that the incidence of gastrointestinal side effects was higher when misoprostol was given orally than when it was given vaginally.

\section{CONCLUSION}

Therapeutic regimen of oral administration of $200 \mathrm{mg}$ mifepristone followed by $600 \mathrm{mg}$ misoprostol vaginal administration after 48 hours was found to be an effective and safest medical termination of pregnancy up to 63 days of gestation. Vaginal route offers early complete abortion (Within 4 hours), a better profile in terms of adverse effects of nausea, vomiting, abdominal pain and diarrhea than oral route. Hence, vaginal route was found be an effective and more acceptable method of medical termination of pregnancy as a day-care procedure.

\section{REFERENCES}

1. Henshaw RC, Naji SA, Russell IT, et al. Comparison of medical abortion with surgical vacuum aspiration: women's preferences and acceptability of treatment. BMJ 1993;307:714-7.

2. Henshaw SK. Induced abortion: a world review, 1990. Fam Plann Perspect. 1990;22:76-89.

3. Grimes DA. Medical abortion in early pregnancy: a review of the evidence. Obstet Gynecol. 1997;89:790-6.

4. UK Multicentre Trial. The efficacy and tolerance of mifepristone and prostaglandin in first trimester termination of pregnancy. $\mathrm{Br} \mathrm{J}$ Obstet Gynecol 1990;97:480-6.

5. World Health Organization (1993). Termination of pregnancy with reduced doses of mifepristone. Br Med J 1993;307:532-7.

6. Baird DT, Sukcharoen N, Thong KJ. Randomized trial of misoprostol and cervagem in combination with a reduced dose of mifepristone for induction of abortion. Hum Reprod. 1995;10:1521-7.

7. Crooif MJ, DeNooyer CCA, Rao BR. Termination of early

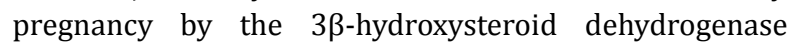
inhibitor epostane. N Engl J Med 1988;319:813.

8. Walter R. Misoprostol for the treatment of peptic ulcer and anti-inflammatory drug induced gastroduodenal ulceration. N Engl J Med 1992;22:1576-9.

9. Birgerson L, Odlind V. Early pregnancy termination with antiprogestins: a comparative clinical study of mifepristone given in two dose regimens and Epostane. FertilSteril. 1987;48:565.

10. Gravanis A, Schaison G, George M. Endometrial and pituitary responses to the steroidal anti-progestin RU 486 in post-menopausal women. J Clin Endocrinol Metab. 1984;60:156.

11. Schindler AM, Zanon P, Obradovic D. Early ultrastructural changes in RU-486-exposed decidua. Gynecol Obstet Invest. 1985;20:62.

12. Kelly RW, Healy DL, Cameron MJ. RU 486 stimulation of $\mathrm{PGF}_{2 a}$ production in isolated endometrial cells in short term culture. In Beaulieu EE, Siegel $S$ (eds): The Antiprogestin Steroid RU 486 and Human Fertility Control. pp. 259, 262 New York, Plenum, 1985.
13. Herrmann WL, Schindler AM, Wyss R. Effects of the antiprogesterone RU 486 in early pregnancy and during the menstrual cycle. In Beaulieu EE, Siegel S (eds): The Antiprogestin Steroid RU 486 and Human Fertility Control. pp. 259, 262 New York, Plenum, 1985.

14. Murry S, Muse K. Mifepristone and first trimester abortion. Clin Obstet Gynaecol 1996;39:474-85.

15. World Health Organization Task Force on Postovulatory Methods of Fertility Regulation. Comparison of two doses of mifepristone in combination with misoprostol for early medical abortion: a randomized trial. Br J Obstet Gynecol 2000; 107:524-30.

16. World Health Organization Task Force on Post-ovulatory Methods of Fertility Regulation. Medical abortion at 57 to 63 days' gestation with a lower dose of mifepristone and gemeprost. A randomized controlled trial. Acta Obstet Gynecol Scand. 2001;80:447-51.

17. El-Refaey H, Rajasekar D, Abdalla M, et al. Induction of abortion with mifepristone (RU 486) and oral or vaginal misoprostol. N Engl J Med 1995;332:983-7.

18. World Health Organization Task Force on Post-ovulatory Methods of Fertility Regulation. Medical abortion at 57 to 63 days' gestation with a lower dose of mifepristone and gemeprost. A randomized controlled trial. Acta Obstet Gynecol Scand. 2001;80:447-51.

19. Schaff EA, Eisinger SH, Stadalius LS, Franks P, Gore BZ, Poppema S. Low-dose mifepristone $200 \mathrm{mg}$ and vaginal misoprostol for abortion. Contracep. 1999;59:1-6.

20. Ashok PW, Penney GC, Flett GMM, et al. An effective regimen for early medical abortion: a report of 2000 consecutive cases. Hum Reproduc. 1998;13:2902-65.

21. Tang OS, Xu J, Cheng L, et al. Pilot study on the use of sublingual misoprostol with mifepristone in termination of first trimester pregnancy up to 9 weeks gestation. Hum Reprod. 2002;17:1738-40.

22. Zieman M, Fong SK, Benowitz NL. Abortion kinetics of misoprostol with oral or vaginal administration. Obstet Gyecol. 1997;90:88-92.

23. Bygdeman M. Pharmacokinetics of Prostaglandins. Best Prac Res Clin Obstet Gynaecol. 2003;17:707-16.

24. Knise B, Poppema S, Creinin MD. Management of side effects and complications in medical abortion. Am J Obstet Gynecol. 2000;183:S65-S73.

25. Spitz IM, Bardin CW, Benton L, et al. Early pregnancy termination with mifepristone and misoprostol in the United States. New Eng Jr Med 1998;338:1241-7.

26. Bartney J, Brown A, Elton R, et al. Double-Blind randomized trial of mifepristone in combination with vaginal gemeprost or misoprostol for induction of abortion up to 63 days gestation. Hum Reprod. 2001;16:2098-102.

27. Tang OS, Chan CCW, Ho PC. A prospective, randomized, placebo-control trial on the use of mifepristone with sublingual or vaginal misoprostol for medical abortions of less than 9 weeks gestation. Hum Reprod 2003;18:2315-8. 


\begin{tabular}{|c|c|c|c|}
\hline & $\begin{array}{c}\text { Oral Misoprostol Group } \\
(n=50)\end{array}$ & $\begin{array}{l}\text { Vaginal Misoprostol Group } \\
(n=50)\end{array}$ & P-value \\
\hline Age, years & $28.2 \pm 5.2$ & $27.4 \pm 4.4$ & 0.336 \\
\hline $\begin{array}{c}\text { Parity } \\
\text { Primigravida } \\
\text { Multigravida }\end{array}$ & $\begin{array}{c}6(12 \%) \\
44(88 \%)\end{array}$ & $\begin{array}{c}9(41 \%) \\
41(82 \%)\end{array}$ & 0.401 \\
\hline $\begin{array}{c}\text { Period of Gestation, Days } \\
\leq 49 \text { days } \\
50-63 \text { days } \\
\end{array}$ & $\begin{array}{r}44.9 \pm 6.9 \\
39(78 \%) \\
11(22 \%) \\
\end{array}$ & $\begin{array}{l}44.6 \pm 7.1 \\
38(76 \%) \\
12(24 \%) \\
\end{array}$ & $\begin{array}{l}0.893 \\
0.812\end{array}$ \\
\hline $\begin{array}{c}\text { History of previous abortion } \\
\text { No previous abortions } \\
\text { Had previous abortions }\end{array}$ & $\begin{array}{c}44(88 \%) \\
6(12 \%) \\
\end{array}$ & $\begin{array}{l}44(88 \%) \\
6(12 \%) \\
\end{array}$ & 1.000 \\
\hline $\begin{array}{c}\text { Previous delivery } \\
\text { Vaginal } \\
\text { LSCS }\end{array}$ & $\begin{array}{l}33(66 \%) \\
11(22 \%)\end{array}$ & $\begin{array}{l}32(64 \%) \\
9(18 \%)\end{array}$ & 0.741 \\
\hline
\end{tabular}

\begin{tabular}{|c|c|c|c|}
\hline & $\begin{array}{c}\text { Oral Misoprostol Group } \\
(n=50)\end{array}$ & $\begin{array}{l}\text { Vaginal Misoprostol Group } \\
(n=50)\end{array}$ & P-value \\
\hline $\begin{array}{l}\text { Abortion } \\
\text { Complete } \\
\text { Incomplete }\end{array}$ & $\begin{array}{l}43(86 \%) \\
7(14 \%)\end{array}$ & $\begin{array}{c}47(94 \%) \\
3(6 \%)\end{array}$ & 0.318 \\
\hline $\begin{array}{c}\text { Parity } \\
\text { Complete Abortion } \\
\text { Primigravida } \\
\text { Multigravida } \\
\text { Incomplete Abortion } \\
\text { Primigravida } \\
\text { Multigravida } \\
\end{array}$ & $\begin{array}{c}5(83 \%) \\
38(86 \%) \\
1(17 \%) \\
6(14 \%)\end{array}$ & $\begin{array}{c}9(100 \%) \\
38(93 \%) \\
0(0 \%) \\
3(7 \%)\end{array}$ & $\begin{array}{l}0.325 \\
0.490\end{array}$ \\
\hline $\begin{array}{c}\text { Period of Gestation } \\
\text { Complete Abortion } \\
\leq 49 \text { days } \\
50 \text { to } 63 \text { Days } \\
\text { Incomplete Abortion } \\
\leq 49 \text { days } \\
50 \text { to } 63 \text { Days }\end{array}$ & $\begin{array}{c}34(87 \%) \\
9(82 \%) \\
5(13 \%) \\
2(18 \%)\end{array}$ & $\begin{array}{c}37(97 \%) \\
10(83 \%) \\
1(3 \%) \\
2(17 \%)\end{array}$ & $\begin{array}{l}0.968 \\
0.260\end{array}$ \\
\hline $\begin{array}{c}\text { History of Previous Abortion } \\
\text { Complete Abortion } \\
\text { Past Abortions } \\
\text { No Previous Abortion } \\
\text { Incomplete Abortion } \\
\text { Past Abortions } \\
\text { No Previous Abortion } \\
\end{array}$ & $\begin{array}{c}5(83 \%) \\
38(86 \%) \\
1(17 \%) \\
6(14 \%)\end{array}$ & $\begin{array}{c}6(100 \%) \\
41(93 \%) \\
0(0 \%) \\
3(7 \%)\end{array}$ & $\begin{array}{l}0.869 \\
0.490\end{array}$ \\
\hline $\begin{array}{c}\text { Type of Previous Delivery } \\
\text { Complete Abortion } \\
\text { LSCS } \\
\text { Vaginal Delivery } \\
\text { Incomplete Abortion } \\
\text { LSCS } \\
\text { Vaginal Delivery }\end{array}$ & $\begin{array}{c}8(72 \%) \\
30(91 \%) \\
3(28 \%) \\
3(9 \%)\end{array}$ & $\begin{array}{c}8(89 \%) \\
30(94 \%) \\
1(11 \%) \\
2(6 \%)\end{array}$ & $\begin{array}{l}1.000 \\
0.635\end{array}$ \\
\hline
\end{tabular}

\begin{tabular}{|c|c|c|c|}
\hline & $\begin{array}{l}\text { Oral Misoprostol } \\
\text { Group }(n=29)\end{array}$ & $\begin{array}{c}\text { Vaginal Misoprostol } \\
\text { Group }(n=33)\end{array}$ & $\begin{array}{c}\mathrm{P}- \\
\text { value }\end{array}$ \\
\hline Induction-Abortion interval, hours & $3.6 \pm 1.4$ & $3.1 \pm 1.2$ & 0.062 \\
\hline $\begin{array}{c}\text { Induction -Abortion interval at cut-off of } 4 \mathrm{hrs} \\
\qquad 4 \text { hours } \\
>4 \text { hours }\end{array}$ & $\begin{array}{c}20(69 \%) \\
9(31 \%)\end{array}$ & $\begin{array}{c}30(91 \%) \\
3(9 \%)\end{array}$ & 0.029 \\
\hline
\end{tabular}

The data depicted above refers to only those women who could definitively appreciate passage of products of conception.

\begin{tabular}{|lccc|}
\hline & $\begin{array}{c}\text { Oral Misoprostol Group } \\
(\mathbf{n = 5 0 )}\end{array}$ & $\begin{array}{c}\text { Vaginal Misoprostol Group } \\
(\mathbf{n}=\mathbf{5 0})\end{array}$ & P-value \\
\hline Onset of bleeding, hours & $3.6 \pm 1.6$ & $3.1 \pm 1.5$ & 0.084 \\
Duration of Bleeding, days & $9.15 \pm 3.37$ & $9.14 \pm 2.34$ & 0.084 \\
\hline \multicolumn{2}{|c|}{ Table 4: Bleeding pattern of treatment regimen in the study } \\
\hline
\end{tabular}

